\title{
La construcción de fronteras políticas internas y la generación de significantes vacíos en el discurso presidencial argentino
}

\begin{abstract}
Natalia Virginia Colombo
UNNE

\section{Resumen}

La presente propuesta aspira a realizar una reflexión acerca del discurso politico desde la perspectiva del discurso populista. Asimismo, propone el análisis de un caso especifico, el actual discurso presidencial argentino, desde el punto de vista de la construcción de la identidad política colectiva del grupo social que se considera el "pueblo" en oposición a un grupo antagónico que "altera" el orden social instituido. Es de destacar que lo mencionado se enmarca en una teoría de la hegemonía (Laclau, 2004), haciendo especial referencia a la construcción de identidades colectivas a través de la generación de fronteras políticas y de significantes vacios. (Laclau, 2005). Por ello en este trabajo me propongo: a) lograr una apropiación y comprensión de categorías teóricas propuestas por Laclau en el marco de una teoría de la hegemonía, b) trabajar con la construcción de identidades colectivas (a través de la generación de fronteras políticas y de significantes vacíos) especialmente la construcción del "pueblo"; c) centralizar el interés en su aplicabilidad al discurso político actual, tomando como ejemplo el discurso presidencial argentino en el marco del actual conflicto con el sector agropecuario.
\end{abstract}

Palabras clave: discurso político- populismo-cadenas equivalenciales-fronteras políticassignificantes vacíos

\section{Introducción}

Esta propuesta tiene como objeto hacer una reflexión acerca del discurso político y realizar el análisis de un caso concreto -el discurso presidencial argentino actual- desde la perspectiva de una teoria de la hegemonia (Laclau, 2004). Considero que dicho discurso recurre a recursos propios del discurso populista a los fines de constituir una identidad política colectiva del grupo social que considera el "pueblo" en oposición al grupo antagónico (el sector agropecuario) que "altera" el orden social instituido. En este sentido, el sujeto de la enunciación se ubica de tal modo ante la problemática del paro agrario que logra construir al "pueblo" como un actor oprimido y víctima de intereses que se concentran en un enemigo general, identificado con el sector agropecuario.

Si bien este discurso reúne las diferencias de la comunidad como válidas, y éste sería un rasgo equivalente dominante (representa a una constelación de sectores de la comunidad) ${ }^{90} \mathrm{se}$

\footnotetext{
${ }^{90} \mathrm{Me}$ refiero al discurso institucional. Discurso institucional: es aquel que intenta hacer coincidir los límites de la formación discursiva con los límites de la comunidad. Por lo tanto, el principio universal de la "diferencialidad" se convertiría en la equivalencia dominante dentro de un espacio comunitario homogéneo.(Laclau, 2005:107) La diferencialidad reclama ser concebida como el único equivalente legítimo: todas las diferencias son igualmente válidas dentro de una totalidad más amplia. (Laclau, 2005:108). El principio de diferencialidad puede constituirse en la única equivalencia dominante.
} 
construye una frontera antagónica a través de la cual se diferencia "el pueblo" del "sector agropecuario"; de un "otro" que se constituye en enemigo. Pero, paradojalmente, se advierte la ambiguedad propia del discurso populista en la construcción de las identidades colectivas.

He trabajado con una muestra de cuatro discursos presidenciales enunciados durante los meses de marzo y abril de 2008, epicentro del conflicto.

Es de destacar que este trabajo no tiene como intención una discusión acerca del populismo como tal, sino la aplicación de una propuesta teórico-metodológica relativa al discurso político populista.

En primer lugar haré una descripción general de las dimensiones del populismo, para luego vincular cada una de ellas con el discurso presidencial propuesto para el análisis.

\subsection{Dimensiones del populismo}

Para Laclau el populismo es una lógica política relacionada con la institución de lo social. Ésta surge de las demandas sociales y en ese sentido es inherente a cualquier proceso de cambio social.

Las dimensiones del populismo son:

1) La unificación de demandas en una cadena equivalencial;

2) La constitución de una frontera interna que divide a la sociedad en dos campos y hace posible la aparición del "pueblo" como actor social,

3) La consolidación de una cadena equivalencial mediante la construcción de una identidad popular que se convierte en algo más que la simple suma de los lazos equivalenciales. (Laclau, 2005; 102) 0 en otras palabras, esta dimensión surge al unificarse las demandas en un sistema estable de significación (el "pueblo"). (Laclau, 2005; 99)

\subsection{La unificación de demandas en una cadena equivalencial}

Creo pertinente hacer referencias a la lógica de la diferencia y a la lógica de la equivalencia, consideradas dos formas de construcción de lo social. En este sentido:

La lógica de la diferencia: es la afirmación de la particularidad cuyos únicos lazos con otras particularidades son de naturaleza diferencial. Por ejemplo, los distintos sectores de la sociedad: policías, docentes, empleados públicos en general, etc. Se diferencian entre sí en cuanto a las diferentes ocupaciones o roles que asumen y tienen peticiones diferentes según el sector en el que se desempeñan.

Lógica de la equivalencia: es la claudicación parcial de la particularidad, destacando lo que todas las particularidades tienen, equivalentemente, en común. Este tipo de construcción de lo social implica el trazado de una frontera antagónica. (Laclau, 2005; 104) Siguiendo con el ejemplo anterior, podemos pensar que en el contexto de crisis internacional y nacional actual todos estos sectores, a pesar de ser diferentes, tienen en común que el pedido de un aumento salarial no es tenido en cuenta por parte del Estado.

La equivalencia y la diferencia son incompatibles entre sí pero se necesitan una a la otra como condiciones necesarias para la construcción de lo social. Lo social no es otra cosa que el locus de esta tensión irresoluble. 
"toda identidad social es constituida por el punto de encuentro entre la equivalencia y la diferencia (...) sin embargo, por otro lado, existe un desnivel esencial en lo social ya que, como hemos visto, la totalización requiere que un elemento diferencial asuma la representación de una totalidad imposible. Así una identidad procedente del campo total de las diferencias encarna esta función totalizadora." (Laclau, 2005; 107)

¿Cómo se construye una identidad social?. Retomo la noción de demanda (o "demanda social"), considerada una unidad de análisis mínima. La demanda puede significar petición o reclamo por parte de un sector social.

Las demandas pueden ser democráticas y populares. Las primeras serán consideradas demandas internas, aisladas (satisfechas o no). En cuanto a las demandas populares, a través de su articulación equivalencial, constituyen una subjetividad social más amplia.

Estas últimas serán consecuencia de una situación de insatisfacción que se prolonga en el tiempo. Por lo tanto, habrá una "acumulación de demandas insatisfechas y una creciente incapacidad del sistema institucional para absorberlas de modo diferencial (cada una separada de las otras) y esto establece entre ellas una relación equivalencial". (Laclau, 2005:98) Este el paso de las demandas democráticas a las demandas populares.

Es decir que, a pesar de la diversidad, las demandas tienen algo en común (equivalente) y es el permanecer insatisfechas. Al retomar aqui el ejemplo anterior, es posible ver que actores sociales diferentes (por ejemplo empleados públicos provinciales: docentes, policías, etc.) con demandas particulares, las unifican en una equivalente: un pedido de aumento salarial al gobierno provincial. Por ser equivalentes se las considera como formando parte de una cadena equivalencial.

Es entonces cuando comienza a conformarse una frontera interna, un antagonismo o "dicotomización del espectro político local a través del surgimiento de una cadena equivalencial de demandas insatisfechas". (Laclau, 2005:99)

En el caso de los discursos presidenciales analizados, es posible advertir que la presidente, como sujeto de la enunciación, resume las demandas particulares de los sectores que representa institucionalmente, en una: "la liberalización de las rutas":

"Yo les pido, humildemente, como Presidenta de todos los argentinos y en nombre de todos los argentinos, que levanten el paro para entonces si dialogar, levanten el paro. Humildemente, levanten el paro y vamos a dialogar" (27-03-08)

"Quiero finalmente pedirles, rogarles encarecidamente a los que aún creen que es bueno cortar caminos para que no pasen alimentos, que es bueno cortar caminos para que no pasen instrumentos para las fábricas, que por favor, en nombre de todo el pueblo y en nombre de ellos mismos, que también son parte del pueblo, adviertan el mal que están haciendo". (01-0408)

"sólo les pido (...) dejen las rutas para que se despejen y los argentinos puedan acceder a los alimentos, las fábricas a los insumos, los comercios a las mercaderías" (01-04-08)

Es posible advertir en estos ejemplos que la unificación de las demandas heterogéneas de los diversos sectores sociales en una cadena equivalencial (los ciudadanos que no pueden 
consumir alimentos, los que no pueden vender productos agropecuarios, los que no reciben insumos para las fábricas, etc. y que piden la libre circulación en las rutas) se concentra en el pedido de restauración del orden social que realiza la presidente al sector agropecuario.

Es de destacar que dentro de la cadena equivalencial de demandas los sectores intervinientes serán nombrados a través de la generalización "argentinos" y "argentinas", totalidad de la que se desprende una parcialidad (antagónica) identificada como: "piqueteros rurales", a veces son "ellos", "los que cortan las rutas", "los que quieren adueñarse de todo", etc. como si no formaran parte de los "argentinos". Resulta interesante lo mencionado en función de que todos los integrantes de los sectores involucrados en el conflicto son (presumiblemente) de nacionalidad argentina. Esto nos da una primera pauta de la conformación de fronteras internas.

\subsection{La creación de fronteras internas}

Para Laclau (2005:110) una frontera antagónica concibe a la sociedad como dos campos irreductibles estructurados alrededor de dos cadenas equivalenciales incompatibles, y está vinculada con una demanda insatisfecha' ${ }^{91}$.

Esta demanda insatisfecha es en realidad una fractura, una falta, una brecha que rompe con el (aparente) dinamismo y armonía de la sociedad. La sociedad concebida como algo pleno y clausurado se ve alterada, lo cual permite el antagonismo y la frontera interna. Sin esta ruptura no hay posibilidad de aparición del "pueblo". (Laclau, 2005; 113)

"Una demanda siempre está dirigida a alguien. Por lo cual nos enfrentamos desde el comienzo con una división dicotómica entre demandas sociales insatisfechas, por un lado, y un poder insensible a ellas, por el otro. Aquí comenzamos a comprender por qué la plebs se concibe a sí misma como el populus la parte como el todo: como la plenitud de la comunidad es precisamente el reverso imaginario de la situación vivida como ser deficiente, aquellos responsables de esta situación no pueden ser una parte legítima de la comunidad; la brecha con ellos es insalvable. (Laclau, 2005; 113)

En el discurso presidencial, tal como mencioné más arriba, es lo que se intenta hacer en nombre de "todos los argentinos", como la plenitud de la comunidad que representa a empresarios, industriales, comerciantes, ciudadanos que no pueden consumir determinados productos, que no pueden viajar, etc. Todos resumen su demanda en el pedido de restauración del orden social a un enemigo, un poder insensible ante las demandas populares: el sector agropecuario, o más concretamente, el poder económico que lo maneja. Son los responsables de la fractura, de la falta (cuya mejor representación icónica e indicial sería el piquete o corte de ruta) que impide el movimiento dinámico y sin sobresaltos de la sociedad.

\footnotetext{
${ }^{91}$ En esta propuesta se ha hecho una primera aproximación al marco teórico-metodológico sugerido desde una de las cadenas equivalenciales: la que pertenece a la esfera del discurso del gobierno. Pero queda pendiente un análisis de la otra esfera del conflicto, el discurso del sector agropecuario. Este discurso si bien se autodenominó como "apolítico" en relación con el conflicto, conlleva en sí mismo muchas caracteristicas del discurso político.
} 
esta vez mucho más violentos y protagonizados por el sector, tal vez, de mayor rentabilidad de los últimos cuatro años y medio o cinco.

Los que hoy amenazan, no al Gobierno, sino a la sociedad con el desabastecimiento de comida,

(pueden) comprarse una 4 por 4 o que vivan bien y que tengan lo que tantisimos argentinos querrían tener; lo que no me parece bien es que además quieran hacerlo a costa de que otros argentinos no puedan acceder a las cuestiones más elementales.

La huelga (...) se la están haciendo a los argentinos, porque las exportaciones siguen viento en popa.

violencia que por cierto he visto mucho más en los sectores de alto poder adquisitivo que en aquellos que no tenian trabajo

piquetes de la abundancia, los piquetes de los sectores de mayor rentabilidad (2503-08)

este Gobierno no está en contra de los hombres y de las mujeres, pequeños productores que trabajan con sus manos el campo. (...) no piden por los pequeños productores, piden por la totalidad de la eliminación de las retenciones, los de los pooles sojeros también, los de los grandes productores también.

¿Cómo vamos a estar en contra de abordar el problema del pequeño productor, pero detrás de los pequeños productores se esconden otros intereses, los de los grandes pooles, que son los que están diciendo que es el Estado el que se quiere llevar toda la ganancia.

decretando un paro, un lock out patronal, contra el Gobierno, en definitiva, contra el pueblo al quitarle los alimentos o al hacer que estos suban producto de la escasez. (27/03/08)

Vi ayer una foto muy impactante de unos piqueteros rurales que hacian un asado que se piensen como parte de un pais, no como propietarios del país, sino como parte

Pero negociar y articular no es decir "o se hace lo que yo digo o no hay diálogo y negociación". Eso no es diálogo y negociación, eso es imposición. (31-03-08)

a los que agravian e insultan, sólo les pido (...) no agravien más al pueblo, dejen las rutas para que se despejen y los argentinos puedan acceder a los alimentos, las fábricas a los insumos, los comercios a las mercaderías. (01-04-08)

Con la generación de la identidad del enemigo se construye la frontera política interna. Sus atributos se resumen en: a) considerarse propietario del país; b) pertenecer a los sectores de mayor rentabilidad, gana mucho dinero; c) es violento, impone y no dialoga, agravia e insulta, e) corta las rutas; f) hace la huelga, un lock aut patronal; e) representa a los grupos económicos y pooles de siembra, no a los pequeños productores, $f$ ) es insensible y especulador.

Pero el enemigo no se concentra exclusivamente en el sector agropecuario, sino que también opera en otro sector: los medios de comunicación. Se construye así, un enemigo "plural", más general: 
Quiero decirles también a quienes tiene la inmensa responsabilidad, la respetabilisima profesión de informar a la sociedad, que lo hagan sin crear antagonismos, sin diferenciar en los colores de piel, por favor, no dividan a los argentinos porque los argentinos queremos estar unidos, solidarios y trabajando. (01-04-08)

\subsection{La cristalización discursiva de una identidad popular}

A través de la creación de fronteras antagónicas vemos, entonces, la aparición del "pueblo": está constituido por los argentinos y argentinas en general (excluyendo al sector agropecuario como si no perteneciera al grupo de "los argentinos"), los hombres y mujeres que defienden su trabajo e ideales; los sindicatos, los movimientos sociales, los ciudadanos que no están en ninguna organización, todos los que militan ( $\sin$ importar el partido político), las madres y abuelas de Plaza de Mayo, los empresarios, los industriales, los gobernantes, en fin, todos los que están en contra del desabastecimiento. Tal como mencioné más arriba, el denominador común entre ellos es una demanda particular que adquiere centralidad: liberación de las rutas, levantamiento de los piquetes; en otras palabras, la restauración del orden social.

De acuerdo con Groppo (2004: 48) ' "el 'pueblo', es precisamente uno de los términos políticos que más claramente alude a un objeto de representación total imposible. En el discurso populista, la idea de "pueblo" nos traslada a una experiencia de lo sublime. El pueblo (...) es la representación del todo, la noción de "pueblo" lleva la marca de ser la representación de la Idea (placer) pero cada enunciación de pueblo implica la partición de ese todo. (...)Ese todo, ese universal que es el pueblo sólo puede ser nombrado a través de ciertas características particulares, o mejor dicho, sólo puede ser significado a través de un particular social que lo especifica y le da sentido. En la brecha inerradicable entre lo inmenso e inconmensurable de lo Universal (la Idea) y lo poco, lo parcial de su representación o instanciación concreta radica la sublimidad del objeto populista. El "pueblo" del discurso populista como objeto sublime nos deja en una aporia/paradoja: aporía entre el deseo de presentar la totalidad tal como es sino a través de un particular determinado."

De allí que en el discurso presidencial se observe lo siguiente:

Quiero convocar, argentinos y argentinas, desde esta histórica Plaza, a todos los argentinos y a todas las argentinas, a todos los sectores económicos y sociales, sindicatos, empresas, (...) Convoco al pueblo argentino, a todos, a este gran acuerdo del Bicentenario de nuestra Patria, de nuestro nacimiento, este 25 de Mayo, desde el fondo de mi corazón. (01-04-08)

Quiero (...) decirles a todos ustedes, que han venido aqui bajo una consigna, la del apoyo al gobierno nacional y popular, (...) a los hombres y mujeres que hoy están aqui han venido también en defensa propia, de sus trabajos, de sus logros, de sus ilusiones, de sus conquistas, de sus esperanzas, porque somos la plaza del reencuentro y la transformación de los argentinos. (01-04-08)

quiero en esta tarde agradecer a todos los que se han acercado a esta plaza, a los sindicatos, a los movimientos sociales, a los miles de ciudadanos y ciudadanas que no están en ninguna organización, que simplemente son eso, ciudadanas y 
ciudadanos que no están de acuerdo con el desabastecimiento, con la especulación, con los que quieren adueñarse de todo. (01-04-08)

La demanda de restauración del orden social que cristaliza la identidad popular ${ }^{92}$, el "pueblo" (como particular), está dividida internamente. Por un lado es una demanda particular; pero por otro lado su propia particularidad comienza a significar algo muy diferente de sí misma: la cadena total de demandas equivalenciales (Laclau, 2005; 124). Va tomando mayor autonomía de éstas ya que, cuanto más extensa es la cadena, menos ligados estarán los significantes a sus demandas particulares.

De tal modo que la identidad popular ("el pueblo") se vuelve cada vez más rica desde un punto de vista extensivo (ya que representa una cadena siempre mayor y plural de demandas) pero se empobrece desde un punto de vista intensivo al despojarse de las particularidades de las demandas sociales heterogéneas que abarca. Es por ello que una identidad popular funciona como un significante tendencialmente vacio ${ }^{93}$. (Laclau , 2005; 125)

El significante vacio ${ }^{94}$ sería de acuerdo con Zizek, un punto nodal (point de capiton), una palabra que en el campo del significante unifica un determinado campo que constituye su identidad como tal. Es la fijación de elementos ideológicos en una red estructurada de significado. (Zizek, 2003: 125).

Esta es una operación hegemónica: no hay hegemonía sin la construcción de una identidad popular a partir de una pluralidad de demandas democráticas. (Laclau, 2005; 124) Esta operación se concreta cuando los objetivos propios del gobierno (a quien el discurso presidencial representa) son trasladados a los objetivos universales del "pueblo" como comunidad ("todos" los sectores que lo conforman y que se ven perjudicados por el paro agrario) ${ }^{95}$.

\footnotetext{
${ }^{92}$ Aunque en este trabajo sólo se trate de analizar palabras, es de destacar que cualquier identidad popular requiere ser condensada no sólo en imágenes o palabras, sino también, en prácticas e instituciones sociales. (Laclau, 2005:138).

${ }^{93}$ Es importante o confundir vacuidad con abstracción: "no concebir al común denominador expresado por el símbolo popular como un rasgo positivo compartido en última instancia por todos los elementos de la cadena. Si esto último fuera así, no habríamos trascendido la lógica de la diferencia. Estaríamos tratando con una lógica abstracta, que sin embargo, pertenecería al orden diferencial y sería como tal, conceptualmente aprehensible. Pero en una relación equivalencial las demandas no comparten nada positivo, sólo el hecho de que todas ellas permanecen insatisfechas. Por lo tanto existe una negatividad especifica inherente al lazo equivalencial." (Laclau, 2005:125)

94 "dentro del sistema de significación existe un punto que es constitutivamente irrepresentable; que, en ese sentido, permanece vacío, pero es un vacio que puede ser significado porque es un vacío dentro de la significación "(Laclau, 2005: 137)

${ }^{95}$ Laclau plantea que la hegemonia es el terreno de la construcción de las relaciones políticas. La lógica hegemónica se resume en que "la posibilidad misma de un discurso universal dirigido a la comunidad como un todo, no depende de un colapso de todas las particularidades, sino de una paradojica relación entre ellas" (Laclau, 2004: 51); "si la hegemonía de un sector particular depende, para su éxito, de que pueda representar sus objetivos propios como aquellos que hacen posible la realización de los objetivos universales de la comunidad, queda claro que esta identificación no es la simple prolongación de un sistema institucional de dominación sino que, por el contrario, toda expansión de esa dominación presupone el éxito de esa articulación entre universalidad y particularidad (es decir, una victoria hegemónica)". (Laclau, 2004: 55); "la emancipación universal se logra solamente a través de una identificación transitoria con los objetivos de un sector social determinado, lo cual significa que es una universalidad contingente que requiere constitutivamente mediación política y relaciones de representación". (Laclau, 2004: 56) Esto es considerado un logro de Gramsci.
} 
De esta manera "pueblo" como significante vacío, como identidad popular, abarcará una gran cantidad de demandas populares (será extensionalmente rica) que se desdibujarán, de algún modo se perderán, bajo la demanda particular que le da sentido ${ }^{96}$.

$Y$ aquí me interesa mostrar con ejemplos, las contradicciones que aparecen en los mismos discursos analizados. Tal como mencioné y demostré a lo largo del trabajo, para la constitución del "pueblo" como identidad popular se lo separó, enfrentó, con un "otro" que cumple el rol del antagonista (el sector agropecuario). Pero vemos también que el "pueblo", paradojalmente, también incluye al sector; es parte constitutiva del mismo:

Yo quiero llamar a todos estos sectores los cuales también son parte de la Argentina, parte importantísima de la Argentina" (25-03-08)

"Quiero finalmente pedirles (...) que por favor, en nombre de todo el pueblo y en nombre de ellos mismos, que también son parte del pueblo, adviertan el mal que están haciendo. (01-04-08)

Quiero decirles que no es una politica antisoja, es una politica esencialmente proArgentina, pro-pueblo, pro-campo también, pro-pueblo. No es una cuestión, como alguien quiere hacerlo aparecer, entre campo e industria, una parte importante de la planta industrial es de la agroindustria, todos son necesarios: el campo, la industria, el comercio, los servicios... (27-03-08)

en nombre de todos los argentinos, de todas las argentinas, en nombre de los productores y horticultores, en nombre de las industrias, de las pymes, de la minipymes familiares, en fin, en nombre de los argentinos (31-03-08)

La explicación a la imprecisión, contradicción, fluctuación la encontramos en la misma esencia del discurso populista (o también podemos decir, politico, tanto de izquierda como de derecha) ya que "intenta operar performativamente dentro de una realidad social que es en gran medida heterogénea y fluctuante. (...) ese momento de vaguedad e imprecisión -que, debería quedar claro, no tiene ninguna connotación peyorativa- como un componente esencial de cualquier operación populista". (Laclau, 2005: 151)

Convoco al pueblo argentino, a todos, a este gran acuerdo del Bicentenario de nuestra Patria, de nuestro nacimiento, este 25 de Mayo, desde el fondo de mi corazón. Y les pido a todos y a todas que me ayuden, quiero que me ayuden a poder seguir luchando por la justicia (...) porque sola no puedo; necesito de la fuerza inagotable e indestructible del pueblo. (01-04-08)

\footnotetext{
96، Si se requiere (...) el pasaje por lo particular, es porque la universalidad no puede estar representada de un modo directo -0 no existe un concepto en correspondencia con el objeto-. Esto significa que el objeto, a pesar de su necesidad, también es imposible. Si su necesidad exige acceder al nivel de la representación, su imposibilidad significa que siempre va a existir una representación distorsionada, es decir que los medios de representación serán constitutivamente inadecuados. Ya sabemos que estos medios de representación son particularidades que, sin dejar de ser particularidades, asumen la función de representación universal. Esto es lo que hay en la raíz de las relaciones hegemónicas". (Laclau, 2004:61).
} 
El "pueblo" se convierte en un punto de fijación nodal, en el nombre de una universalidad imposible de alcanzar, de una plenitud ausente, en un significante vacío. Es posible advertir, entonces, un discurso universal dirigido a la comunidad como un todo, pero que depende de una paradójica relación entre las particularidades para consumar una operación hegemónica.

"Las identidades son siempre los sitios de tensión entre estos dos movimientos opuestos y el precario equilibrio que logran establecer entre ellos. El resultado es una ambiguedad ideológica necesaria "(Laclau, 2005: 140)

\section{Conclusiones}

En este trabajo he tratado de aplicar categorias teóricas relativas al discurso populista a un caso del discurso presidencial argentino, en el marco de la actual crisis entre el gobierno y el sector agropecuario.

He podido comprobar la construcción de una identidad popular enmarcada en el "pueblo" en oposición al poder económico del sector agropecuario, con la finalidad perlocutiva de generar un espacio político diferente, un "otro" del cual se diferencia el "argentino medio", que quiere comprar, vender, viajar, producir, etc. y que conforma dicha identidad popular. Éste se ve imposibilitado de hacerlo debido a la alteración del orden social, a partir del paro agrario y el desabastecimiento que provoca. Esta alteración o fractura muestra la necesidad de un cambio.

Pero el "pueblo" como identidad popular resulta inconmensurable y en su rol de significante vacío o punto nodal va desdibujando las demandas particulares que 10 conformaron.

De esta manera el efecto que logra el discurso es una ambigledad e imprecisión, propia del discurso populista, ya que trata de abarcar y representar a una gran heterogeneidad de demandas sociales. En esta articulación entre universalidad y particularidad es posible advertir la búsqueda de consolidación de un discurso hegemónico. 


\section{Referencias}

GROPPO, A. (2004) El populismo y lo sublime. En: Studia Politicae. Núm. 02. Publicada por la Facultad de Ciencia Política y Relaciones Internacionales de la Universidad Católica de Córdoba. Córdoba, Argentina.

LACLAU, E. (2005) La razón populista. Buenos Aires, Fondo de Cultura Económica. Cap. IV y V.

LACLAU, E. y MOUFFE, Ch. (2006) Hegemonía y estrategia socialista. Hacia una radicalización de la democracia. Buenos Aires, Fondo de Cultura Económica.

LACLAU, E. (2004) Identidad y hegemonía: el rol de la universalidad en la constitución de lógicas políticas. En: Contingencia, hegemonía y universalidad. Diálogos contemporáneos de la izquierda. Buenos Aires, Fondo de Cultura Económica.

ZIZEK, S. (2005) El sublime objeto de la ideología. Buenos Aires, Fondo de Cultura Económica.

Colombo, Natalia Virginia es Doctora en Semiótica por la Universidad Nacional de Córdoba (Centro de Estudios Avanzados y Facultad de Filosofia y Humanidades). Actualmente, se desempeña como Profesora Adjunta, a cargo y con dedicación exclusiva, en la Cátedra Semiótica de la Facultad de Humanidades de la UNNE. Desde el año 2002 participa de manera ininterrumpida en distintos proyectos de investigación acreditados y ha difundido sus trabajos en numerosos eventos cientificos, nacionales e internacionales, como también, en revistas especializadas. 